\title{
Inhibition of endogenous hydrogen sulfide production exacerbates the inflammatory response during urine-derived sepsis-induced kidney injury
}

\author{
HUILI QIU $^{1 *}$, XIAN CHEN $^{2 *}$, ZHIGANG LUO $^{2}$, LIWEN ZHAO $^{2}$, TAO ZHANG $^{2}$,

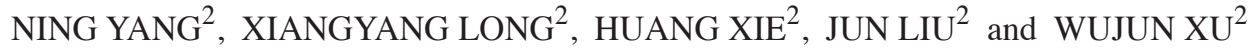 \\ ${ }^{1}$ School of Nursing, Changsha Medical University, Changsha, Hunan 410219; ${ }^{2}$ Department of Urology, \\ Second Affiliated Hospital of The University of South China, Hengyang, Hunan 421001, P.R. China
}

Received September 22, 2016; Accepted June 22, 2017

DOI: $10.3892 /$ etm.2018.6520

\begin{abstract}
The aim of the present study was to investigate the effects of endogenous $\mathrm{H}_{2} \mathrm{~S}$ on the inflammatory response in kidneys following urine-derived sepsis-induced injury. A rabbit model of urine-derived sepsis was established by injecting Escherichia coli into the ligated ureter. Rabbits were randomly divided into the, control, sham, sepsis and DL-propargylglycine (PAG)-treated sepsis groups. The same surgical procedure except for the bacteria injection was performed for the sham group, while the control group was fed on normal diet without any additional treatments. The monitoring of vital signs, routine blood examinations and kidney function tests were performed prior to surgery and at $12,24,36$ and $48 \mathrm{~h}$ following surgery. The serum $\mathrm{H}_{2} \mathrm{~S}$ concentration and kidney cystathionine- $\gamma$-lyase (CSE) activity were determined following surgery. Pathological alterations were assessed by hematoxylin and eosin (H\&E) staining, and the expression levels of inflammation-associated cytokines were detected by western blot analysis. The results demonstrated that rabbits in the sepsis and PAG groups exhibited a significant increase in rectal temperature, heart rate and respiratory rate following surgery when compared with the sham group; with the PAG group demonstrating the greatest increase. In addition, white cell counts and creatinine and urea nitrogen levels were significantly elevated following surgery in the sepsis and PAG groups when compared with the sham group. The serum $\mathrm{H}_{2} \mathrm{~S}$ concentration and kidney CSE activity were significantly reduced in the sepsis group
\end{abstract}

Correspondence to: Professor Wujun Xu, Department of Urology, Second Affiliated Hospital of The University of South China, 35 Jiefang Road, Hengyang, Hunan 421001, P.R. China

E-mail: xwj272201034@yeah.net

*Contributed equally

Key words: urine-derived sepsis, endogenous $\mathrm{H}_{2} \mathrm{~S}$, inflammatory response, inflammation-associated cytokines compared with the sham group, and a significant decrease in the levels of these factors were observed in the PAG group compared with the sepsis group. H\&E staining indicated obvious structural abnormalities in kidney tissues in the sepsis group, which were exacerbated by PAG treatment. In addition, PAG treatment significantly increased the expression levels of nuclear factor- $\mathrm{\kappa B}$ and interleukin- 6 , and decreased transforming growth factor- $\beta 1$ expression when compared with the sepsis group. In conclusion, PAG significantly exacerbated urine-derived sepsis-induced kidney injury potentially via altering the expression of inflammation-associated cytokines.

\section{Introduction}

Sepsis is a systemic inflammatory response syndrome (SIRS) that occurs as a result of infection. Severe sepsis and septic shock are important risk factors for mortality in critically ill patients following major surgery (1-4). Urine-derived sepsis is diagnosed when there is clear evidence of urinary tract infection and SIRS (5). Early intervention for sepsis and SIRS may rapidly and effectively influence inflammatory responses, which is important for the prevention and treatment of multiple organ dysfunction syndrome $(6,7)$. A number of signaling molecules have been implicated in the pathogenesis of urine-derived sepsis; one of which is the gaseous signaling molecule, $\mathrm{H}_{2} \mathrm{~S}(8,9)$.

$\mathrm{H}_{2} \mathrm{~S}$ is produced primarily via the sulfur amino acid metabolism signaling pathway, whereby L-cysteine is catalyzed by cystathionine- $\beta$-synthase (CBS) and cystathionine- $\gamma$-lyase (CSE) (10). Endogenous $\mathrm{H}_{2} \mathrm{~S}$ has been demonstrated to be extensively involved in a variety of physiological and pathological processes in vivo, such as inflammatory responses $(11,12)$. Previous studies have indicated that CBS and CSE expression is detectable in kidney tissues, and that the endogenous production of $\mathrm{H}_{2} \mathrm{~S}$ serves an important role in the kidney function $(13,14)$. It has been demonstrated that low concentrations of $\mathrm{H}_{2} \mathrm{~S}$ reduce lipopolysaccharide (LPS)-induced SIRS (15), and increased endogenous $\mathrm{H}_{2} \mathrm{~S}$ generation inhibits airway inflammation to a certain degree (16). In addition, treatment with NaHS has been demonstrated to inhibit LPS-induced inflammatory lesions in endothelial cells (17), and prevent intestinal 
ischemia-associated inflammatory injury (18). Furthermore, $\mathrm{H}_{2} \mathrm{~S}$ accelerates the migration of neutrophils (19) and alleviates acute lung injuries induced by sepsis, thus increasing the survival rate of septic mice (20). A previous study suggested that exogenous $\mathrm{H}_{2} \mathrm{~S}$ treatment may downregulate the expression of nuclear factor $-\kappa \mathrm{B}(\mathrm{NF}-\kappa \mathrm{B})$ and tumor necrosis factor (TNF)- $\alpha$ and upregulate the expression of IL-10, to alleviate urine-derived sepsis-induced kidney injury (21).

In the present study, the effects of endogenous $\mathrm{H}_{2} \mathrm{~S}$ on the inflammatory response in kidneys following urine-derived sepsis-induced injury were investigated. A rabbit model of urine-derived sepsis was first established by the injection of bacteria, and DL-propargylglycine (PAG), an inhibitor of CSE that reduces endogenous $\mathrm{H}_{2} \mathrm{~S}$ production, was used to treat the rabbits. The expression levels of inflammation-associated cytokines, NF- $\kappa \mathrm{B}$, transforming growth factor- $\beta 1$ (TGF- $\beta 1$ ), and interleukin-6 (IL-6), in the kidney tissues of rabbits were subsequently detected and analyzed.

\section{Materials and methods}

Animal grouping and modeling. A total of 32 male rabbits (age, 4-5 months; weight, 1.80-2.20 kg), were provided by the Department of Experimental Animals in University of South China (Hengyang, China). The rabbits were housed at room temperature in 50-60\% humidity with one rabbit per cage in a $12 \mathrm{~h}$ dark/light cycle. The rabbits were provided with water and commercial rabbit pellets ad libitum. The animals were divided at random into control, sham, sepsis and PAG groups ( $n=8$ rabbits/group). All animal experiments were approved by the Ethics Committee of The Second Affiliated Hospital of Nanhua University (Hengyang, China).

The rabbit model of urine-derived sepsis was established as described previously (21). Briefly, a vertical incision was made along the left abdominal rectus muscle, and the middle section of ureter was freed and ligated. A suspension of Escherichia coli $\left[\right.$ E. coli; $10^{8}$ cells/ml; ATCC, 25922; American Type Culture Collection, Manassas, VA, USA;] was then injected into the ureter at the proximal end of the ligation site at a dose of $0.5 \mathrm{ml} / \mathrm{kg}$ body weight. The incision was subsequently sutured and rabbits were fed a normal diet. Food was given at the indicated time points but the rabbits had free access to water. The urine-derived sepsis model was additionally established in rabbits in the PAG group, with the addition of a single intraperitoneal injection of $37.5 \mathrm{mg} / \mathrm{kg}$ body weight PAG immediately following the surgical operation (Sigma-Aldrich; Merck KGaA, Darmstadt, Germany). The same surgical procedure was performed in rabbits in the sham group, excluding the injection of the bacteria. Rabbits in the control group were fed on normal diet without any additional treatments.

Monitoring of vital signs. For each rabbit, the rectal temperature (using a rectal thermometer), heart rate (using a watch and stethoscope) and respiratory rate (by counting the nose hair swing frequency) were recorded prior to surgery, and at 12, 24, 36 and $48 \mathrm{~h}$ following surgery.

White blood cell counts. A total of 1-2 ml peripheral blood samples were collected from the ear vein prior to surgery, and at 12, 24, 36 and $48 \mathrm{~h}$ following surgery. White blood cells were counted using a hemocytometer.

Kidney function test. Peripheral blood samples were collected prior to surgery, and at 12, 24, 36 and $48 \mathrm{~h}$ following surgery. The levels of creatinine and urea nitrogen were measured using an automatic biochemical analyzer (AU800; Olympus Corporation, Tokyo, Japan).

Hematoxylin and eosin $(H \& E)$ staining. At $48 \mathrm{~h}$ following surgery, the rabbits were anesthetized and their left kidneys were removed. Kidney tissues were subsequently fixed with $4 \%$ formaldehyde at room temperature for 24-48 h, embedded in paraffin and cut into $5-\mu \mathrm{m}$-thick sections. Tissues were then subject to $\mathrm{H} \& \mathrm{E}$ staining at $60^{\circ} \mathrm{C}$ for $30 \mathrm{~min}$, and visualized under a light microscope at magnification, $\mathrm{x} 400$. In total, 10 fields of view were randomly selected and observed from each section.

Serum $\mathrm{H}_{2} \mathrm{~S}$ concentration. At $48 \mathrm{~h}$ following surgery, the rabbits were anesthetized, and approximately 5-7 ml venous blood from the left kidney was collected and centrifuged at $1,500 \mathrm{x} \mathrm{g}$ at room temperature for $10 \mathrm{~min}$. A total of $0.5 \mathrm{ml}$ zinc acetate solution (1\%) was subsequently added to $0.1 \mathrm{ml}$ test plasma, followed by $0.5 \mathrm{ml}$ dimethyl-p-phenylenediamine sulfate/ $\mathrm{HCl}$ solution $(20 \mathrm{mM} / 7.2 \mathrm{M})$ and $0.4 \mathrm{ml}$ ferric chloride/ $\mathrm{HCl}$ solution $(30 \mathrm{mM} / 1.2 \mathrm{M})$. The solution was incubated at room temperature for $20 \mathrm{~min}$, and $1 \mathrm{ml}$ trichloroacetic acid $(10 \%)$ and $2.5 \mathrm{ml} \mathrm{ddH}_{2} \mathrm{O}$ were subsequently added. Samples were then centrifuged at 2,500 x g at room temperature for $8 \mathrm{~min}$, the supernatant was collected and the absorbance at $679 \mathrm{~nm}$ was read using a spectrophotometer. The $\mathrm{H}_{2} \mathrm{~S}$ concentration was calculated according to a standard curve.

CSE activity. At $48 \mathrm{~h}$ following surgery, rabbits were anesthetized and the left kidneys were removed. A total of $200 \mathrm{mg}$ tissue was mixed with $10 \%(\mathrm{w} / \mathrm{v}) 50 \mathrm{mM} / 1$ potassium phosphate buffer ( $\mathrm{pH} 6.8$ ), and then homogenized on ice. Following centrifugation at $4{ }^{\circ} \mathrm{C}$ at $2,500 \mathrm{x}$ g at room temperature for $10 \mathrm{~min}$, the supernatant was collected, and $80 \mu \mathrm{l} \mathrm{L}$-cysteine $(0.5 \mathrm{M})$ plus $3.52 \mathrm{ml} 5$-pyridoxal phosphate $(0.5 \%)$ was added to $400 \mu \mathrm{l}$ tissue homogenate. A total of $0.5 \mathrm{ml}$ zinc acetate (1\%) was then added to the central chamber; in which folded filter paper was placed. The reaction system and the central chamber were placed in a $25-\mathrm{ml}$ conical flask filled with nitrogen, and incubated in a water bath at $37^{\circ} \mathrm{C}$ for $90 \mathrm{~min}$. The reaction was terminated by adding $0.5 \mathrm{ml}$ trichloroacetic acid $(50 \%)$, and the flask was sealed with a paraffin membrane. Following a further $60 \mathrm{~min}$ incubation at $37^{\circ} \mathrm{C}$, the mixture in the central chamber was transferred to a fresh tube containing

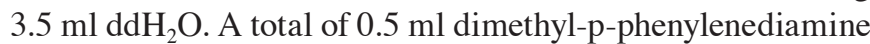
sulfate/ $\mathrm{HCl}$ solution $(20 \mathrm{mM} / 7.2 \mathrm{M})$ and $0.4 \mathrm{ml}$ ferric chloride/ $\mathrm{HCl}$ solution $(30 \mathrm{mM} / 1.2 \mathrm{M})$ was added, and the solution was incubated at $37^{\circ} \mathrm{C}$ for $20 \mathrm{~min}$ prior to centrifugation at $1,500 \mathrm{x} \mathrm{g}$ at $37^{\circ} \mathrm{C}$ for $5 \mathrm{~min}$. The absorbance at $670 \mathrm{~nm}$ was read using a spectrophotometer, and the $\mathrm{H}_{2} \mathrm{~S}$ concentration was calculated according to a standard curve. CSE activity (nM/min/mg) was set as the concentration of $\mathrm{H}_{2} \mathrm{~S}$ produced during $1 \mathrm{~min}$ in $1 \mathrm{mg}$ kidney tissue. 
Western blot analysis. The expression levels of NF-kB, IL-6, and TGF- $\beta 1$ in kidney tissues were determined by western blot analysis. The kidney tissue (harvested $48 \mathrm{~h}$ post surgery) was lysed with a PBS lysis buffer $(0.24 \mathrm{~g}$ potassium dihydrogen phosphate, $1.44 \mathrm{~g}$ disodium hydrogen phosphate, $0.2 \mathrm{~g}$ potassium chloride, $8 \mathrm{~g}$ sodium chloride in $1,000 \mathrm{ml}$ solution; $\mathrm{pH}$ 7.4) and total protein was extracted according to the manufacturer's protocol. Sample protein concentrations were determined using the bicinchoninic acid assay method (Beyotime Institute of Biotechnology, Shanghai, China). A total of $50 \mu \mathrm{g}$ protein sample was loaded per lane and separated by $10 \%$ SDS-PAGE, and then electronically transferred onto a polyvinylidene difluoride membrane. The membranes were subsequently blocked with $5 \%$ non-fat milk at $37^{\circ} \mathrm{C}$ for $1 \mathrm{~h}$ prior to incubation with primary antibodies against NF- $\mathrm{kB}$ (bsm-33117M; 1:500 dilution), IL-6 (bs-4587M; 1:500 dilution), TGF- $\beta 1$ (bsm-33287M; 1:500 dilution), or $\beta$-actin (bsm-33036M; 1:5,000 dilution) (all purchased from BIOSS, Beijing, China) at $4^{\circ} \mathrm{C}$ overnight. Following washing with Tris-buffered saline and Tween-20 solution, the membrane was incubated with a goat anti-mouse immunoglobulin $\mathrm{M} /$ horseradish peroxidase antibodies (bs-0368G-HRP; 1:10,000; BIOSS) at room temperature for $2 \mathrm{~h}$. Protein bands were visualized using an enhanced chemiluminescence method (Beyotime Institute of Biotechnology), according to the manufacturer's protocol and band densities were analyzed using the GSD8000 image analysis system (UVP, Cambridge, UK).

Statistical analysis. The results are expressed as the mean \pm standard deviation. The SPSS software program (version, 18.0; SPSS, Inc., Chicago, IL, USA) was used to perform statistical analyses. The results were analyzed by one-way analysis of variance followed by a post hoc least significant difference test. $\mathrm{P}<0.05$ was considered to indicate a statistically significant difference.

\section{Results}

PAG exacerbates pathophysiological alterations in a rabbit model of urine-derived sepsis. Monitoring of vital signs, routine blood examinations and kidney function tests were performed in rabbits from the control, sham, sepsis and PAG groups prior to surgery, and at 12, 24, 36 and $48 \mathrm{~h}$ following surgery. Based on the monitoring of vital signs, no significant differences in rectal temperature, heart rate and respiratory rate among these four groups was observed prior to surgery (Fig. 1A-C). By contrast, the rectal temperature, heart rate and respiratory rate were significantly elevated at $12 \mathrm{~h}$ following surgery in the sepsis and PAG groups compared with the sham group $(\mathrm{P}<0.05)$; however, a gradual plateauing in the level of these factors was observed at $48 \mathrm{~h}$ following surgery (Fig. 1A-C). In the sepsis group, the rectal temperature, heart rate and respiratory rate of rabbits were significantly elevated at $12 \mathrm{~h}$ following surgery compared with the sham group $(\mathrm{P}<0.05)$, and continued to increase at 24,36 and $48 \mathrm{~h}$ following surgery. In addition, the rectal temperature, heart rate, and respiratory rate of rabbits in the PAG group were significantly elevated following surgery when compared with the sham group and the sepsis group $(\mathrm{P}<0.05$; Fig. 1A-C). There was no significant difference between the control group and the sham group.
Similar results were observed for the routine blood examinations and kidney function tests in the control, sham, sepsis and PAG groups. Prior to surgery, no significant differences in the white cell count and the levels of creatinine and urea nitrogen among these four groups were observed (Fig. 1D-F). In the sepsis and PAG groups, the white cell counts and the levels of creatinine and urea nitrogen were significantly elevated following surgery when compared with the sham group at the corresponding time points $(\mathrm{P}<0.05)$, with increased levels of these factors observed in the PAG group compared with the sepsis group at all time points (Fig. 1D-F). No significant differences were observed between the control group and the sham group. These results indicated the successful establishment of a rabbit model of urine-derived sepsis, which was considered to be suitable for subsequent experiments. In addition, PAG treatment was demonstrated to exacerbate sepsis-associated pathophysiological alterations.

$P A G$ reduces the serum $\mathrm{H}_{2} \mathrm{~S}$ concentration and kidney CSE activity in a rabbit model of urine-derived sepsis. The effects of PAG on the concentration of serum $\mathrm{H}_{2} \mathrm{~S}$ and kidney CSE activity in a rabbit model of urine-derived sepsis were subsequently investigated. As demonstrated in Fig. 2A, no significant difference in the serum $\mathrm{H}_{2} \mathrm{~S}$ concentration between the control and sham groups at $48 \mathrm{~h}$ following surgery was observed. By contrast, the serum $\mathrm{H}_{2} \mathrm{~S}$ concentration was significantly reduced in the sepsis group at $48 \mathrm{~h}$ following surgery when compared with the sham group $(\mathrm{P}<0.05$; Fig. $2 \mathrm{~A})$. In addition, a significant reduction the serum $\mathrm{H}_{2} \mathrm{~S}$ concentration was observed in the PAG group at $48 \mathrm{~h}$ after surgery when compared with the sham and sepsis groups $(\mathrm{P}<0.05$; Fig $2 \mathrm{~A})$. Similar results were observed for the kidney CSE activity detection. When compared with the sham group, CSE activity in kidney tissues of rabbits in the sepsis group were significantly decreased at $48 \mathrm{~h}$ following surgery $(\mathrm{P}<0.05)$, with a greater reduction in kidney CSE activity in the PAG group compared with the sham and sepsis groups $(\mathrm{P}<0.05$; Fig. 2B). These results suggest that PAG treatment further decreased the serum $\mathrm{H}_{2} \mathrm{~S}$ concentration and kidney CSE activity in a rabbit model of urine-derived sepsis, which suggests that PAG exacerbates disease progression.

PAG exacerbates histopathological kidney lesions in a rabbit model of urine-derived sepsis. In order to investigate the effects of PAG on the formation of histopathological kidney lesions in a rabbit model of urine-derived sepsis, H\&E staining was performed. As indicated in Fig. 3, no obvious histopathological alterations in the kidney tissues of rabbits in the control and sham groups were observed (Fig. 3). However, in the sepsis group, H\&E staining indicated obvious structural abnormalities in the kidney tissues, including an abnormal glomerulus morphology, glomus atrophy and deformation and kidney capsule expansion. In addition, edema and necrosis were observed in the kidney tubular epithelial cells, with detached necrotic cells blocking the lumen. Furthermore, the size of the renal capsule and renal tubular lumen were significantly expanded and significant kidney interstitium hyperemia and edema, and abundant inflammatory cell infiltration were observed in the kidney tissues of rabbits in the sepsis group (Fig. 3). When compared with the sepsis group, these 
A
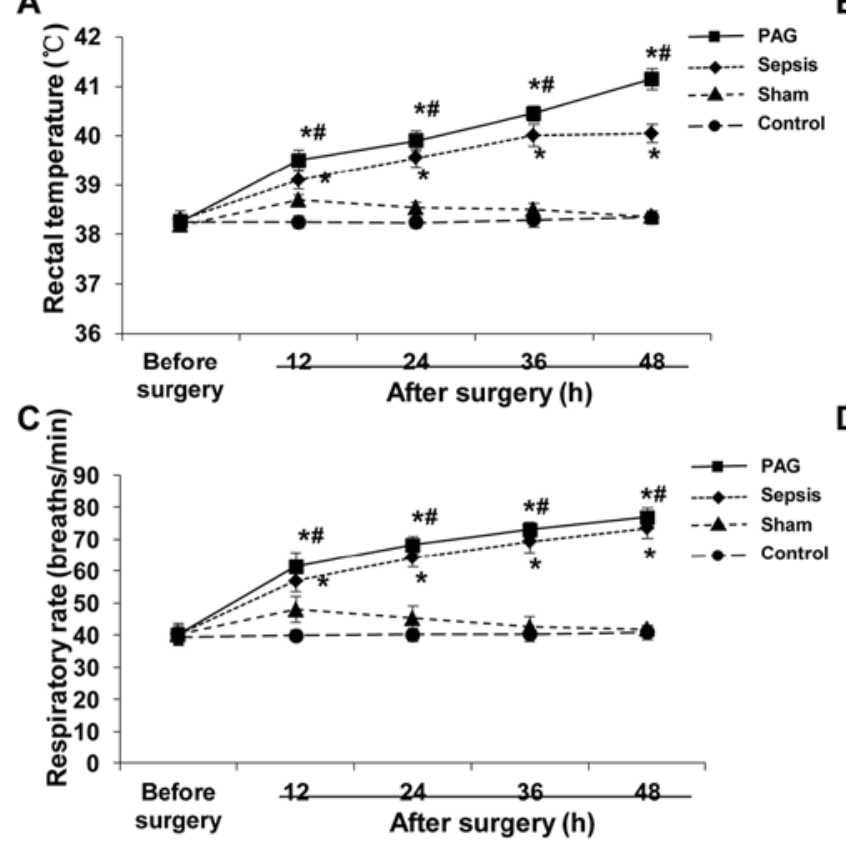

E

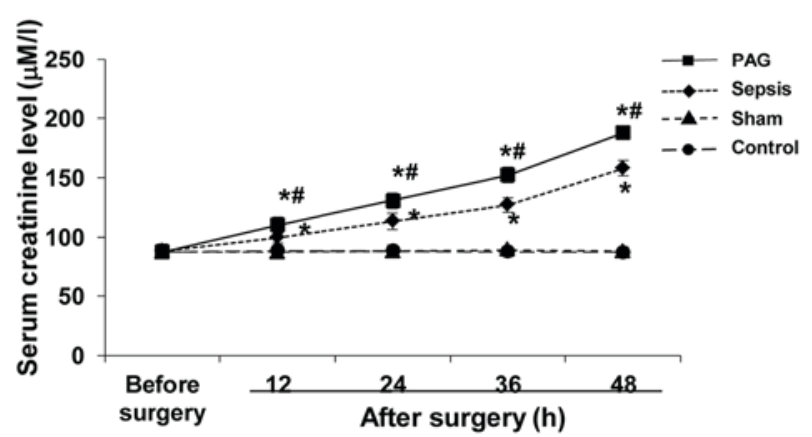

B
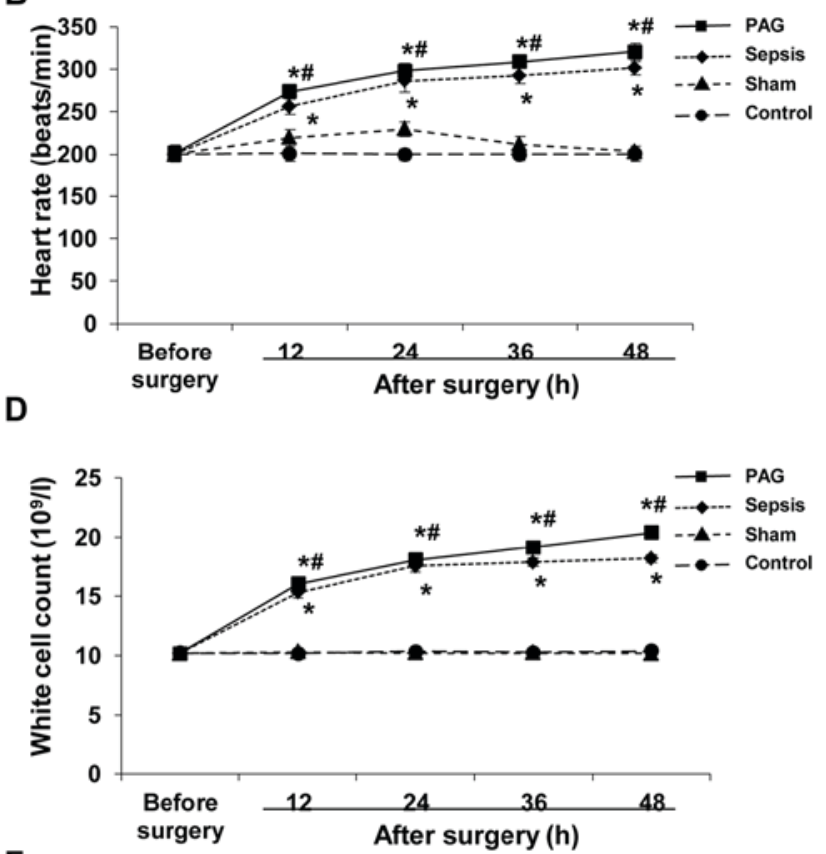

$\mathbf{F}$

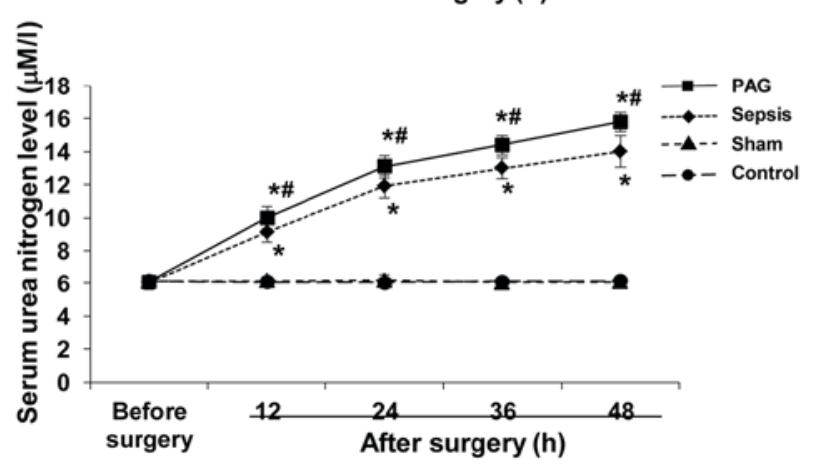

Figure 1. Effect of PAG on pathophysiological alterations in a rabbit model of urine-derived sepsis. Vital sign monitoring, routine blood examinations and kidney function tests were performed in rabbits from the control, sham, sepsis and PAG groups prior to surgery, and at 12, 24, 36 and 48 h following surgery. The (A) rectal temperature, (B) heart rate, (C) respiratory rate, (D) white cell count, and serum levels of (E) creatinine and (F) urea nitrogen were detected and analyzed. ${ }^{*} \mathrm{P}<0.05$ vs. sham group; ${ }^{*} \mathrm{P}<0.05$ vs. sepsis group. PAG, DL-propargylglycine.

histopathological alterations were significantly exacerbated in the PAG group (Fig. 3). These results provide evidence to suggest that treatment with PAG worsens the development of histopathological kidney lesions in a rabbit model of urine-derived sepsis.

$P A G$ alters the expression levels of inflammation-associated cytokines in kidney tissues in a rabbit model of urine-derived sepsis. To investigate the effects of PAG on the expression levels of NF- $\kappa$ B, IL- 6 and TGF- $\beta 1$ in the kidney tissues of rabbits with urine-derived sepsis, western blot analysis was performed. As indicated in Fig. 4, no significant difference in the protein expression levels of NF- $\mathrm{KB}$, IL- 6 and TGF- $\beta 1$ was observed between the control and sham groups at $48 \mathrm{~h}$ following surgery. However, the expression levels of NF- $\kappa B$ and IL-6 in kidney tissues were significantly elevated in the sepsis group when compared with the sham group $(\mathrm{P}<0.05)$. The expression of NF- $\mathrm{KB}$ and IL-6 were significantly elevated in the PAG group when compared with sham and sepsis groups $(\mathrm{P}<0.05$; Fig. 4$)$. In addition, TGF- $\beta 1$ protein expression was significantly elevated in the sepsis group compared with the sham group $(\mathrm{P}<0.05)$. However, compared with the sepsis group, the expression level of TGF- $\beta 1$ was significantly reduced in the PAG group $(\mathrm{P}<0.05)$; however, its expression remained significantly higher than the sham group $(\mathrm{P}<0.05)$. No significant differences were observed between the control group and the sham group. These results suggest that PAG treatment may significantly increase the expression levels of NF- $\mathrm{KB}$ and IL-6, and decrease TGF- $\beta 1$ expression in kidney tissues, in a rabbit model of urine-derived sepsis.

\section{Discussion}

In the present study, a rabbit model of urine-derived sepsis was established by injecting $E$. coli into the ligated ureter (21). Rabbits were subsequently treated with $\mathrm{PAG}$, which is an inhibitor of CSE. The effect of endogenous $\mathrm{H}_{2} \mathrm{~S}$ on the inflammatory response in kidneys following urine-derived sepsis was subsequently investigated. The results demonstrated that the rectal temperature, heart rate and respiratory rate of rabbits in the sham group were elevated at $12 \mathrm{~h}$ following 

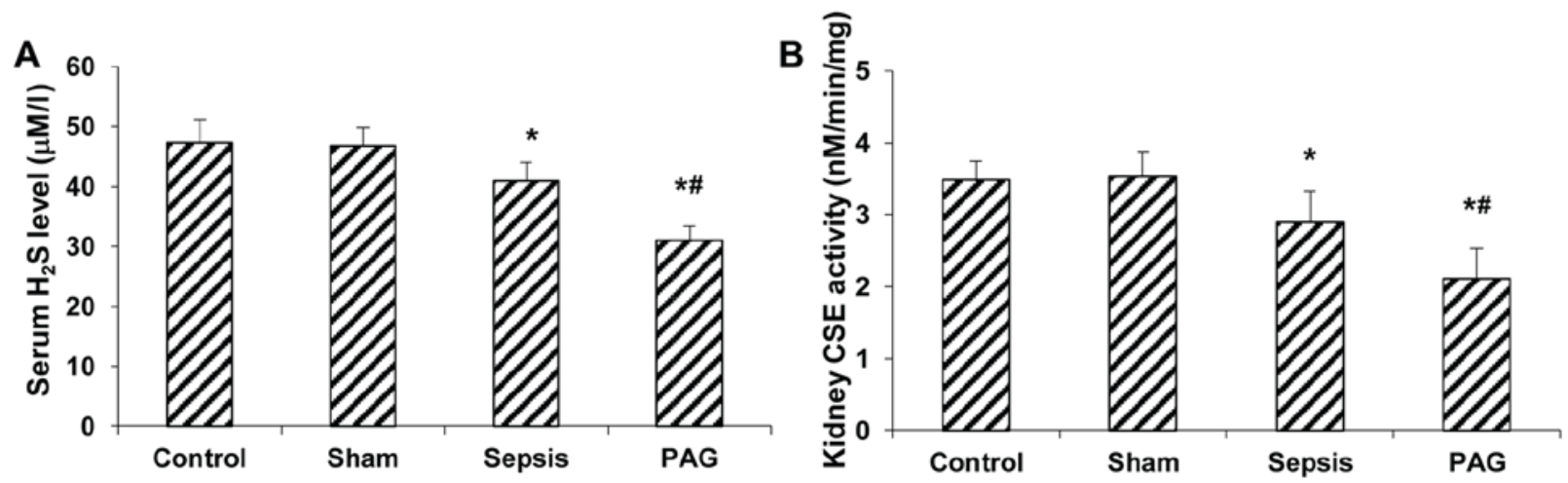

Figure 2. Effect of PAG on serum $\mathrm{H}_{2} \mathrm{~S}$ concentration and kidney CSE activity in a rabbit model of urine-derived sepsis. The (A) serum $\mathrm{H}_{2} \mathrm{~S}$ concentration and (B) kidney CSE activity were measured in rabbits from the control, sham, sepsis and PAG groups at $48 \mathrm{~h}$ following surgery. ${ }^{~} \mathrm{P}<0.05$ vs. sham group; ${ }^{*} \mathrm{P}<0.05$ vs. sepsis group. PAG, DL-propargylglycine; CSE, cystathionine- $\gamma$-lyase.

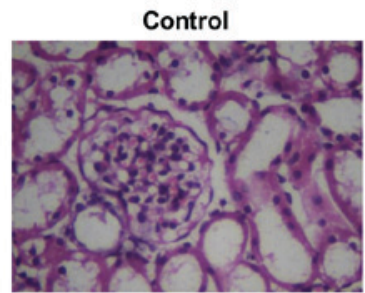

Sepsis

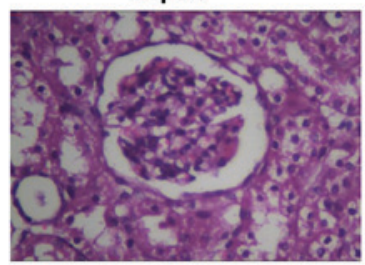

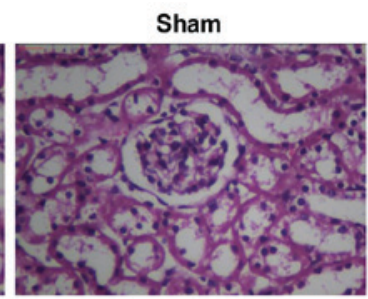

PAG

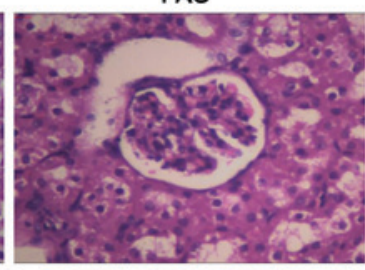

Figure 3. Effect of PAG on the development of histopathological kidney lesions in a rabbit model of urine-derived sepsis. Hematoxylin and eosin staining was performed to determine alterations in the histopathology of kidney tissues in rabbits from the control, sham, sepsis and PAG groups at $48 \mathrm{~h}$ following surgery (magnification, $\mathrm{x} 400$ ). PAG, DL-propargylglycine.

surgery; however these returned to levels similar to that of the control group at 36-48 h following surgery. Similar results were observed for the white cell counts, and the serum levels of creatinine and urea nitrogen. However, a significant and time-dependent increase in rectal temperature, heart rate, respiratory rate and white cell count was observed in the sepsis group when compared with the sham group. In addition, pathological alterations were observed in the kidney tissues of rabbits in the sepsis group. According to the diagnostic criteria of urine-derived sepsis described in a previous study by Yao et al (22), the model generated in the present study was considered to have been successfully established and suitable for subsequent investigations.

$\mathrm{NF}-\kappa \mathrm{B}$ activates the expression of a variety of inflammatory factors, and is a key factor involved in the systemic inflammatory response $(23,24)$. During bacterial infection, endotoxins enter the blood stream and form a complex with binding proteins in the cytoplasm. It has been demonstrated that in sepsis, due to the over-reaction of the host immune system against bacteria and toxins, the pro-inflammatory cytokines (TNF- $\alpha, N F-\kappa B$ and IL-6) were initially produced, followed by the rapid release of anti-inflammatory factors (including, TGF- $\beta$ and IL-10), which induced alternating peaks of pro-inflammatory and anti-inflammatory cytokines in the blood circulation $(23,25)$. In addition, endotoxin may enter the blood circulation and form a complex with binding proteins in the plasma, specifically binding to molecular receptors (such as CD14) on the surface of the cell membranes (26). The complex then specifically binds to receptors, such as cluster of differentiation 14, on the cellular membrane (27), which leads to transduction of signaling pathways into the cytoplasm via Toll-like receptors. The TNF or tyrosine protein kinase signaling pathways are then activated, thus leading to the activation of $\mathrm{NF}-\kappa \mathrm{B}$ in the cytoplasm and its translocation to the nucleus, which initiates the transcription of target genes (28). In addition, endotoxins are able to activate $\mathrm{NF}-\kappa \mathrm{B}$ in the cytoplasm via plant disease resistance-like proteins (29). Activated NF- $\kappa \mathrm{B}$ induces the expression and release of specific pro-inflammatory cytokines, including TNF- $\alpha$, IL-6 and IL-8 (30), which subsequently enhances the activation of $\mathrm{NF}-\kappa \mathrm{B}$ and amplifies the inflammatory response. Anti-inflammatory cytokines, such as TGF- $\beta$ and IL-10, are simultaneously synthesized and released, thereby reducing the expression of pro-inflammatory mediators and preventing the development of inflammatory response-associated syndromes. Sepsis occurs a result of an excessive inflammatory response (31).

IL-6 exhibits pro- and anti-inflammatory effects. IL-6 induces the phosphorylation of signal transducer and activator of transcription 3 to prevent T-cell apoptosis. This leads to the accumulation of circulating T-cells and the development of chronic inflammation, which is inhibited by the anti-IL-6 receptor antibody (32). A previous study demonstrated that alterations in the level of IL- 6 may be a useful early indicator of inflammation and sepsis (33). TGF- $\beta$ has been demonstrated to exert immunosuppressive functions, which serve important roles in congenital and acquired immunity (34). TGF- $\beta$ downregulates the expression of pro-inflammatory cytokines and antagonizes the development of an excessive inflammatory response. A previous study demonstrated that endotoxins significantly increase the expression of pro-inflammatory cytokines, such as TNF- $\alpha$ and IL-1 $\beta$, as well as their receptors in mice with a defect in TGF- $\beta$, which leads to an excessive inflammatory response (35). 
A

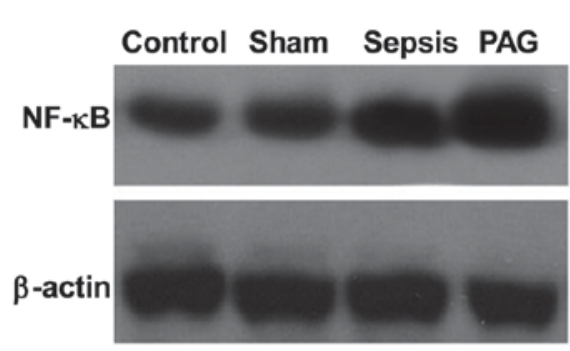

B

C
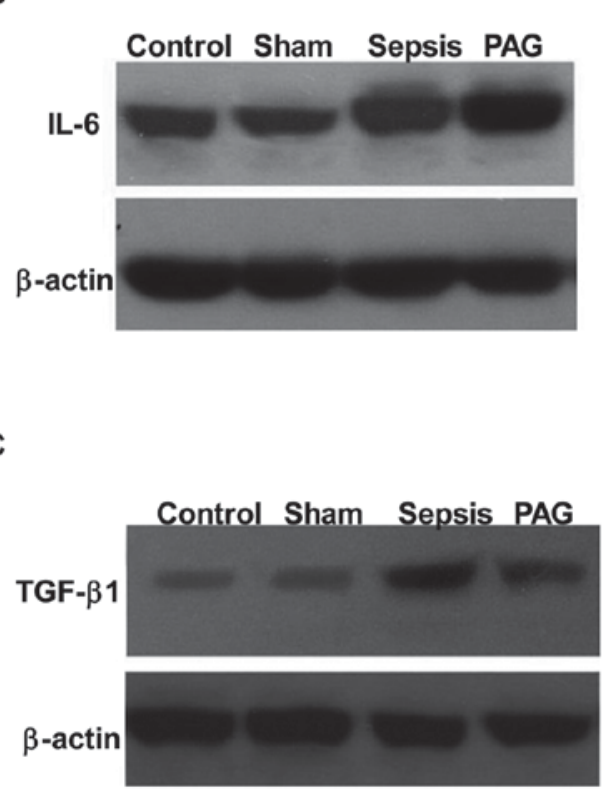
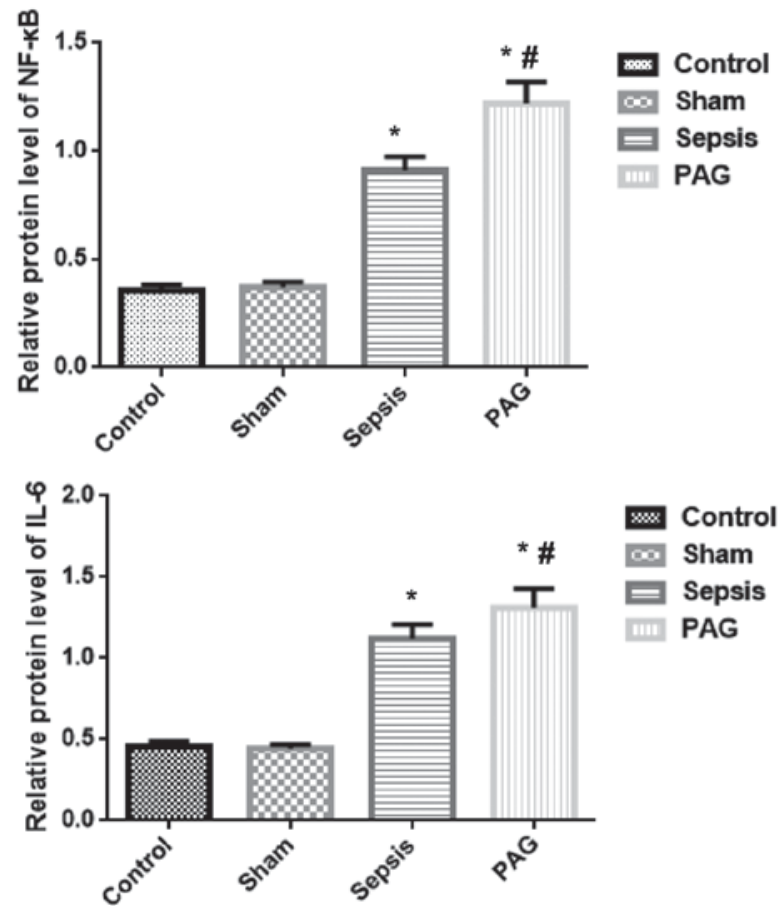

这

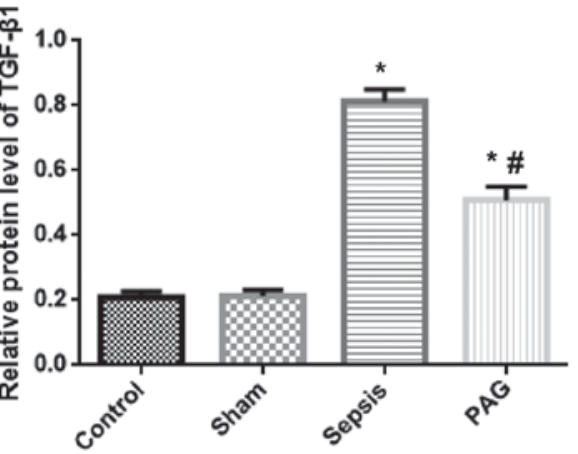

Figure 4. Effect of PAG on the protein expression levels of inflammation-associated cytokines in a rabbit model of urine-derived sepsis. Western blot analysis of the protein expression levels of (A) NF- $\kappa \mathrm{B}$, (B) IL- 6 and (C) TGF- $\beta 1$ in kidney tissues are presented on the left and the quantified results are presented on the right. ${ }^{\mathrm{P}}<0.05$ vs. sham group; ${ }^{\#} \mathrm{P}<0.05$ vs. sepsis group. $\mathrm{PAG}, \mathrm{DL}-$ propargylglycine; NF- $\kappa \mathrm{B}$, nuclear factor- $\kappa \mathrm{B}$; IL-6, interleukin-6; TGF- $\beta 1$, transforming growth factor- $\beta 1$.

$\mathrm{H}_{2} \mathrm{~S}$ is widely involved in a number of biological processes in various tissues and/or organs (36). Treatment with PAG, an inhibitor of CSE, may inhibit the endogenous production of $\mathrm{H}_{2} \mathrm{~S}$ (22). Previous studies have demonstrated that, $\mathrm{H}_{2} \mathrm{~S}$ inhibits the excessive activation of $\mathrm{NF}-\kappa \mathrm{B}$, reduces the production of pro-inflammatory cytokines and increases the expression of anti-inflammatory factors, thereby reducing sepsis-induced injuries $(21,37)$. In addition, $\mathrm{H}_{2} \mathrm{~S}$ may reduce the production and release of a variety of pro-inflammatory cytokines by inhibiting the $\mathrm{NF}-\kappa \mathrm{B} /$ cyclooxygenase-2 signaling pathway, thus preventing an excessive inflammatory response (37). The results of the present study demonstrated that the expression levels of NF- $\mathrm{B}$, IL- 6 and TGF- $\beta 1$ in kidney tissues were significantly upregulated in the sepsis group when compared with the sham group at $48 \mathrm{~h}$ following surgery. Following treatment with $\mathrm{PAG}$, endogenous $\mathrm{H}_{2} \mathrm{~S}$ generation and kidney CSE activity were significantly reduced when compared with the untreated sepsis group, which is consistent with the results presented by Ma et al (38). In addition, PAG treatment significantly upregulated the expression of NF- $\kappa \mathrm{B}$ and IL-6, and downregulated the expression of TGF- $\beta 1$ in kidney tissues at $48 \mathrm{~h}$ following surgery when compared with the sepsis group. Furthermore, histopathological alterations in the kidney tissues were exacerbated, and white cell counts were further elevated by PAG treatment in the rabbit model of urine-derived sepsis, thus indicating decreased kidney function. The effects of PAG in the rabbit model of urine-derived sepsis may be associated with the altered expression levels of NF- $\kappa \mathrm{B}$, IL- 6 and TGF- $\beta 1$ in kidney tissues. Future comprehensive studies are required to investigate this hypothesis further.

In conclusion, the results of the current study indicated that PAG treatment decreased $\mathrm{H}_{2} \mathrm{~S}$ production and CSE activity in a rabbit model of urine-derived sepsis. In addition, treatment with PAG significantly exacerbated urine-derived sepsis-induced pathological alterations in kidney tissues, which may have been associated with the altered expression levels of inflammation-associated cytokines. These results provide novel information that may facilitate the development of clinical strategies for the prevention and treatment of urine-derived sepsis and associated kidney injury. 


\section{Acknowledgements}

Not applicable.

\section{Funding}

The present study was supported by the Hunan Provincial Natural Science Foundation (grant no. 13JJ9009).

\section{Availability of data and materials}

The datasets used and/or analyzed during the current study are available from the corresponding author on reasonable request.

\section{Authors' contributions}

HLQ and XC established the rabbit model of urine-derived sepsis, monitored the vital signs, performed HE staining and western blot analysis and drafted the manuscript. ZGL counted the white blood cells. LWZ performed the kidney function test. TZ and NY measured the serum $\mathrm{H} 2 \mathrm{~S}$ concentration. XYL, HX and JL conducted the CSE activity test. HLQ and XC performed the statistical analysis. WJX conceived and designed the study and revised the manuscript. All authors read and approved the final manuscript.

\section{Ethics approval and consent to participate}

The study was approved by the Ethics Committee of The Second Affiliated Hospital of Nanhua University.

\section{Patient consent for publication}

Not applicable.

\section{Competing interests}

The authors declare that they have no competing interests.

\section{References}

1. Stevenson EK, Rubenstein AR, Radin GT, Wiener RS and Walkey AJ: Two decades of mortality trends among patients with severe sepsis: A comparative meta-analysis. Crit Care Med 42: 625-631, 2014.

2. Levy MM, Dellinger RP, Townsend SR, Linde-Zwirble WT, Marshall JC, Bion J, Schorr C, Artigas A, Ramsay G, Beale R, et al: The Surviving Sepsis Campaign: Results of an international guideline-based performance improvement program targeting severe sepsis. Crit Care Med 38: 367-374, 2010.

3. Martin GS, Mannino DM, Eaton S and Moss M: The epidemiology of sepsis in the United States from 1979 through 2000. N Engl J Med 348: 1546-1554, 2003.

4. Cawcutt KA and Peters SG: Severe sepsis and septic shock: Clinical overview and update on management. Mayo Clin Proc 89: 1572-1578, 2014

5. Grabe M, Bjerklund-Johansen TE, Botto H, Cek M, Naber KG, Pickard RS, Tenke P, Wagenlehner F and Wullt B: Guidelines on urological infections. European Association of Urology, Arnhem, 2013. https://uroweb.org/wp-content/ uploads/18_Urological-infections_LR.pdf. Limited Update March 2013.
6. Fry DE: Sepsis, systemic inflammatory response, and multiple organ dysfunction: The mystery continues. Am Surg 78: 1-8, 2012.

7. Makkonen J, Pietilainen KH, Rissanen A, Kaprio J and Yki-Jarvinen H: Genetic factors contribute to variation in serum alanine aminotransferase activity independent of obesity and alcohol: A study in monozygotic and dizygotic twins. J Hepatol 50: 1035-1042, 2009.

8. Zhou CF and Tang XQ: Hydrogen sulfide and nervous system regulation. Chin Med J (Engl) 124: 3576-3582, 2011.

9. Wang R: Hydrogen sulfide: The third gasotransmitter in biology and medicine. Antioxid Redox Signal 12: 1061-1064, 2010.

10. Kimura H: Hydrogen sulfide: Its production, release and functions. Amino Acids 41: 113-121, 2011.

11. Whiteman M and Winyard PG: Hydrogen sulfide and inflammation: The good, the bad, the ugly and the promising. Expert Rev Clin Pharmacol 4: 13-32, 2011.

12. Calvert JW, Coetzee WA and Lefer DJ: Novel insights into hydrogen sulfide-mediated cytoprotection. Antioxid Redox Signal 12: 1203-1217, 2010.

13. Lobb I, Sonke E, Aboalsamh G and Sener A: Hydrogen sulphide and the kidney: Important roles in renal physiology and pathogenesis and treatment of kidney injury and disease. Nitric Oxide 46: 55-65, 2015.

14. Koning AM, Frenay AR, Leuvenink HG and van Goor $\mathrm{H}$ : Hydrogen sulfide in renal physiology, disease and transplantation-the smell of renal protection. Nitric Oxide 46: 37-49, 2015.

15. Tokuda K, Kida K, Marutani E, Crimi E, Bougaki M, Khatri A, Kimura $\mathrm{H}$ and Ichinose F: Inhaled hydrogen sulfide prevents endotoxin-induced systemic inflammation and improves survival by altering sulfide metabolism in mice. Antioxid Redox Signal 17: 11-21, 2012.

16. Zhang P, Li F, Wiegman CH, Zhang M, Hong Y, Gong J, Chang Y, Zhang JJ, Adcock I, Chung KF and Zhou X: Inhibitory effect of hydrogen sulfide on ozone-induced airway inflammation, oxidative stress, and bronchial hyperresponsiveness. Am J Respir Cell Mol Biol 52: 129-137, 2015.

17. Pan LL, Liu XH, Gong QH, Wu D and Zhu YZ: Hydrogen sulfide attenuated tumor necrosis factor-alpha-induced inflammatory signaling and dysfunction in vascular endothelial cells. PLoS One 6: e19766, 2011.

18. Zuidema MY, Peyton KJ, Fay WP, Durante W and Korthuis RJ: Antecedent hydrogen sulfide elicits an anti-inflammatory phenotype in postischemic murine small intestine: Role of heme oxygenase-1. Am J Physiol Heart Circ Physiol 301: H888-894, 2011.

19. Spiller F, Orrico MI, Nascimento DC, Czaikoski PG, Souto FO, Alves-Filho JC, Freitas A, Carlos D, Montenegro MF, Neto AF, et al: Hydrogen sulfide improves neutrophil migration and survival in sepsis via K+ATP channel activation. Am J Respir Crit Care Med 182: 360-368, 2010.

20. Ang SF, Sio SW, Moochhala SM, MacAry PA and Bhatia M: Hydrogen sulfide upregulates cyclooxygenase-2 and prostaglandin E metabolite in sepsis-evoked acute lung injury via transient receptor potential vanilloid type 1 channel activation. J Immunol 187: 4778-4787, 2011.

21. Chen X, Xu W, Wang Y, Luo H, Quan S, Zhou J, Yang N, Zhang T, Wu L, Liu J, et al: Hydrogen sulfide reduces kidney injury due to urinary-derived sepsis by inhibiting NF-kappaB expression, decreasing TNF-alpha levels and increasing IL-10 levels. Exp Ther Med 8: 464-470, 2014.

22. Yao Y, Sheng $\mathrm{Z}$ and Lin $\mathrm{H}$ : New understanding of the definition and diagnosis of sepsis. Zhongguo Wei Zhong Bing Ji Jiu Yi Xue 16: 321-324, 2004.

23. Souza AC, Volpini RA, Shimizu MH, Sanches TR, Camara NO, Semedo P, Rodrigues CE, Seguro AC and Andrade L: Erythropoietin prevents sepsis-related acute kidney injury in rats by inhibiting nuclear-factor kappa $\mathrm{B}$ and upregulating endothelial nitric oxide synthase. Am J Physiol Renal Physiol 302: 1045-1054, 2012

24. Xu H, Ye X, Steinberg H and Liu SF: Selective blockade of endothelial NF-kappaB pathway differentially affects systemic inflammation and multiple organ dysfunction and injury in septic mice. J Pathol 220: 490-498, 2010.

25. Sadik NA, Mohamed WA and Ahmed MI: The association of receptor of advanced glycated end products and inflammatory mediators contributes to endothelial dysfunction in a prospective study of acute kidney injury patients with sepsis. Mol Cell Biochem 359: 73-81, 2012. 
26. Peri F, Piazza M, Calabrese V, Damore G and Cighetti R: Exploring the LPS/TLR4 signal pathway with small molecules. Biochem Soc Tran 38: 1390-1395, 2010.

27. Peri F, Piazza M, Calabrese V, Damore G and Cighetti R: Exploring the LPS/TLR4 signal pathway with small molecules. Biochem Soc Trans 38: 1390-1395, 2010.

28. Kim TH, Yoon SJ and Lee SM: Genipin attenuates sepsis by inhibiting toll-like receptor signaling. Mol Med 18: 455-465, 2012

29. Thome M, Hofmann K, Burns K, Martinon F, Bodmer JL, Mattmann C and Tschopp J: Identification of CARDIAK, a RIP-like kinase that associates with caspase-1. Curr Biol 8: 885-888, 1998.

30. Liu Z, Guan Y, Sun X, Shi L, Liang R, Lv X and Xin W: HSV-1 activates NF-kappaB in mouse astrocytes and increases TNF-alpha and IL-6 expression via Toll-like receptor 3. Neurol Res 35: 755-762, 2013.

31. Sagy M, Al-Qaqaa Y and Kim P: Definitions and pathophysiology of sepsis. Curr Probl Pediatr Adolesc Health Care 43: 260-263, 2013

32. Mudter J and Neurath MF: Il-6 signaling in inflammatory bowel disease: pathophysiological role and clinical relevance. Inflamm Bowel Dis 13: 1016-1023, 2007.

33. Tambuyzer T, De Waele T, Chiers K, Berckmans D, Goddeeris BM and Aerts JM: Interleukin-6 dynamics as a basis for an early-warning monitor for sepsis and inflammation in individual pigs. Res Vet Sci 96: 460-463, 2014.

34. Hiraki S, Ono S, Tsujimoto H, Kinoshita M, Takahata R, Miyazaki H, Saitoh D and Hase K: Neutralization of interleukin-10 or transforming growth factor-beta decreases the percentages of CD4+CD25+ Foxp3+ regulatory T cells in septic mice, thereby leading to an improved survival. Surgery 151: 313-322, 2012
35. McCartney-Francis N, Jin W and Wahl SM: Aberrant toll receptor expression and endotoxin hypersensitivity in mice lacking a functional TGF-beta 1 signaling pathway. J Immunol 172: 3814-3821, 2004

36. Kimura H, Shibuya N and Kimura Y: Hydrogen sulfide is a signaling molecule and a cytoprotectant. Antioxid Redox Signal 17: 45-57, 2012.

37. Yang C, Yang Z, Zhang M, Dong Q, Wang X, Lan A, Zeng F, Chen $\mathrm{P}$, Wang $\mathrm{C}$ and Feng J: Hydrogen sulfide protects against chemical hypoxia-induced cytotoxicity and inflammation in $\mathrm{HaCaT}$ cells through inhibition of $\mathrm{ROS} / \mathrm{NF}-\kappa \mathrm{B} / \mathrm{COX}-2$ pathway. Plos One 6: e21971, 2011.

38. Ma B, Liang G, Zhang F, Chen Y and Zhang H: Effect of hydrogen sulfide on restenosis of peripheral arteries after angioplasty. Mol Med Rep 5: 1497-1502, 2012.

This work is licensed under a Creative Commons Attribution-NonCommercial-NoDerivatives 4.0 International (CC BY-NC-ND 4.0) License. 